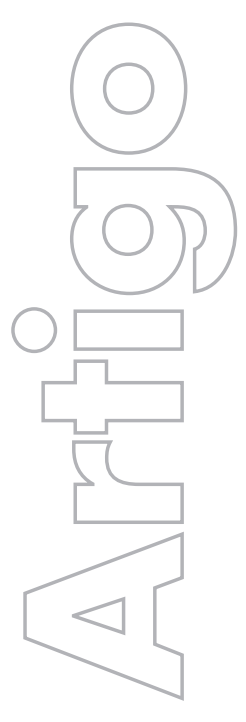

revista

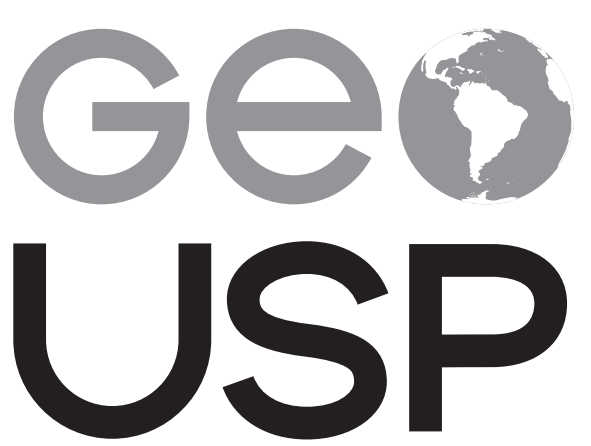

espaço e tempo

Volume $23 \cdot n^{\circ} 2$ (2019)

ISSN 2179-0892
Análise da sustentabilidade de projetos de assentamentos rurais em

\section{Goiás}

\author{
Júnio Gregório Roza Santos \\ Universidade Federal de Goiás - Brasil \\ Selma Simões Castro \\ Universidade Federal de Goiás - Brasil
}

p. $394-416$

Como citar este artigo:

SANTOS, J. G. R.; CASTRO, S. S. Análise da sustentabilidade de projetos de assentamentos rurais em Goiás. Geousp - Espaço e Tempo (Online), v. 23, n. 2, p. 394-416, ago. 2019. ISSN 2179-0892.

Disponível em: https://www.revistas.usp.br/geousp/article/ view/158368. doi: https://doi.org/10.11606/issn.2179-0892. geousp.2019.158368.

\section{(c) $($ i) $(9)$}

Este artigo está licenciado sob a Creative Commons Attribution 4.0 License. 


\title{
Análise da sustentabilidade de projetos de assentamentos rurais em Goiás
}

\section{Resumo}

insucesso da política de Projetos de Assentamentos Rurais (PA) no país é amplamente conhecido e estudado por meio de metodologias de avaliação do seu desempenho, sendo que poucos utilizam indicadores e respectivos parâmetros integrados de avaliação da sustentabilidade. $\bigcirc$ objetivo deste artigo é apresentar os resultados de aplicação de metodologia baseada na análise de funções de uso das terras (FUT), como condicionantes estruturantes da sustentabilidade, aplicada a PA do estado de Goiás, comparativamente bem e malsucedidos, representativos de duas regiões de contraste ambiental e socioeconômico: o nordeste e o sul goiano. Os resultados indicaram que o PA do nordeste goiano pode ser considerado insustentável, mas preserva grande parte do cerrado nativo, o que lhe atribui uma qualificação contraditória. Já o PA do sul goiano, sustentável, tem maior equilibrio entre os fatores sociais, econômicos e ambientais estudados, embora preserve apenas a cobertura obrigatória pela legislação ambiental.

Palavras-chave: Assentamentos rurais. Funções de uso das terras. Potencial de uso das terras. Sustentabilidade.

\section{Analysis of sustainability of rural settlement projects in Goiás}

\begin{abstract}
The failure of the Rural Settlement Projects (PA) policy in the country is widely known and studied through performance evaluation methodologies, with few using indicators and their integrated parameters for sustainability assessment. This article aims to present the results of applying a methodology based on the analysis of Land Use Functions (LUF), as structural determinants of sustainability, applied to PA of the state of Goiás, comparatively well and unsuccessful, representative of two well contrasted environmental and socioeconomically, the Northeast of Goiás and the South of Goiás. The results indicated that the PA of the Northeast of Goiás can be considered unsustainable, but preserves a large part of the native Cerrado, which gives it a contradictory qualification. On the other hand, the
\end{abstract}


PA of the South Goiano, sustainable, exhibits a greater balance between the social, economical and environmental factors studied, although it only preserves the obligatory coverage by the environmental legislation.

Keywords: Rural settlements. Land use functions. Land use potential. Sustainability.

\section{Analyse de la durabilité des projets de règlement rural à Goiás}

\section{Resumée}

L'échec de la politique des projets de règlement rural (AP) au Brésil est largement connu et étudié par méthodologies visant l' évaluation de ses performances en tant que développement durable, cependant peu ont utilisé des indicateurs et paramètres intégrés d' évaluation. Cet article présente les résultats de l'application de la méthodologie basée sur l'analyse des Fonctions d'Utilisation des Terres, à propôs des contraintes structurales pour le développement durable. La recherche a comparée deux AP de l'état de Goiás, un bien et un autre infructueuse, statistiquement représentants de deux régions environnementales et socioéconomiques bien contrastées, le nord-est et le sud de l'état de Goiás. Les résultats indiquent que le AP du nord-est a été considéré comme non durable, parce que il est mal exploité, par contre il préserve encore une grande partie de la couverture originelle, ce que lui confere une qualification contradictoire. Le AP du Sud a été considéré durable, parce que il montre un plus grand équilibre entre les facteurs sociaux, économiques et environnementaux.

Mots-clés: Règlement rural. Fonctions d'utilisation des terres. Potentiel d'utilisation des terres. Durabilité.

\section{Introdução}

As primeiras ações de reforma agrária no território goiano ocorreram com a criação do assentamento Mosquito, em 1986, no município de Goiás, no oeste do estado. Desde então novos PA têm sido criados para atender a demanda de trabalhadores rurais sem terra que reivindicam esse direito. Até o momento, foram assentadas no estado de Goiás 13.019 famílias em 308 PA (Incra, 2017).

Santos e Castro (2016) caracterizaram os PA goianos quanto a sua área, número de famílias, distribuição geográfica e aspectos relativos à qualidade das terras para o aproveitamento produtivo. Os autores identificaram concentração de PA e do número total de famílias 
assentadas na região do nordeste goiano, em oposição à região sul. $\bigcirc$ estudo verificou que o grande contraste entre essas regiões se devia principalmente ao histórico de ocupação, à socioeconomia, ao potencial produtivo das terras e ao uso e ocupação do solo. $\bigcirc$ sul favoreceu a exploração econômica por culturas voltadas tanto para a subsistência (feijão, arroz), como para a comercialização (soja, milho, cana-de-açúcar), em função do relevo suave a suave ondulado, facilmente mecanizável, e solos com alto potencial produtivo desde que corrigida sua acidez e pobreza nutricional naturais. Já o nordeste, onde o potencial produtivo das terras é limitado, sobressaiu-se a pecuária extensiva e a silvicultura em áreas de aptidão agrícola média e baixa e a preservação ambiental em áreas altamente frágeis e restritivas. Todavia, os autores lembram que as condições produtivas das terras não podem ser olhadas de forma isolada e nem se constituírem em determinantes do desenvolvimento dos PA, devendo ser avaliadas desde a fase de seleção de terras para sua criação, assim como para orientar sistemas produtivos eficientes em acordo com as suas potencialidades e limitações.

Kageyama et al. (1990), Graziano da Silva (1996, 2000), Bittencourt et al. (1999) e Sparovek $(2003,2005)$, entre outros autores, discutiram a diversidade e imbricação dos fatores de desenvolvimento dos pequenos agricultores, incluindo os PA, com base em um rol de indicadores socioeconômicos, ambientais e políticos. A literatura tem mostrado que o sucesso ou o fracasso de um PA decorre da integração entre as condições existentes para a exploração das terras como crédito agrícola e assistência técnica, as formas de organização interna das famílias, a qualidade das intervenções dos órgãos envolvidos com a reforma agrária ao longo das fases de estruturação e consolidação do PA, a capacidade do assentamento em integrar a sua produção interna à economia regional e o seu potencial em garantir a geração de emprego e renda.

Nessa mesma perspectiva e dando continuidade aos trabalhos de Santos e Castro (2016) e de Santos (2018), a pesquisa baseou-se no pressuposto de que o potencial de uso das terras dos PA é um dos condicionantes da sua sustentabilidade. Para tanto, adotou-se a metodologia proposta por Pérez-Soba et al. (2008), que propõe a análise de funções de uso das terras (FUT), consideradas como estruturantes do desenvolvimento sustentável. Assim, o objetivo foi testar essa metodologia na análise da sustentabilidade em dois PA goianos representativos de duas regiões do estado, o nordeste e o sul goiano, contrastadas em diversos aspectos considerados, respectivamente, mal e bem sucedidos em termos de PA da Reforma Agrária em Goiás.

\section{Principais diferenças regionais entre o nordeste e o sul goiano}

Goiás se situa na região geoeconômica do Centro-Oeste do Brasil a qual, a partir da década de 1960-70, marcada por sua baixa integração econômica com o Sudeste brasileiro, principal região econômica nacional na época, foi alvo de intervenções desenvolvimentistas, por meio de políticas federais e estaduais, voltadas à expansão da fronteira agrícola e modernização da sua base técnica, inaugurando o processo de modernização da agricultura no Centro-Oeste (Kageyama et al., 1990; Estevam, 1998; Graziano da Silva, 2000; Hogan; Cunha; Carmo, 2002). As políticas e os planos de desenvolvimento implementados foram responsáveis pela sua integração e submissão econômica a uma lógica produtiva global (lanni, 1984; Arrais et al., 2010; Mielitz Neto, Melo, Maia, 2010; Pessôa, V.; Inocêncio, 2014).

Em Goiás, Calaça e Dias (2010), Correia (2010) e Arrais et al. (2010) destacam que o processo de capitalização vivenciado intensamente pelo estado durante a expansão da fronteira agrícola não ocorreu de forma socioespacialmente homogênea e, por isso, ocasionou o que 
os autores chamaram de diferenciação no grau de modernização do território goiano. Arrais et al. (2010) consideram que se produziu uma notável desigualdade econômica entre o norte e o sul goianos efetivada, principalmente pela incorporação de áreas para atender à demanda de produção agropecuária, aos programas de Colonização e a uma rede urbana que se construía e se hierarquizava a partir de Goiânia.

Castro e Xavier (2006) adotaram a teoria dos lugares centrais (Christaller, 1966) para explicar por que o sul goiano foi privilegiado pelas vantagens comparativas eminentemente regionais, que viabilizariam uma maior e mais rápida capitalização e, por isso, o seu desenvolvimento foi estimulado pelo investimento de capitais e de incentivos fiscais consolidando a região como um lugar central. Miziara (2006), Prado e Miziara e Ferreira (2012), entre outros autores, lembram que essas vantagens regionais ligavam-se à disponibilidade de terras com boa aptidão agrícola (Figura 1), cultiváveis por meio da adoção das novas técnicas agronômicas de correção e adubação dos solos naturalmente ácidos e pobres em nutrientes e da infraestrutura viária já disponível na região. A Figura 1 ilustra o contraste de aptidão agrícola das duas regiões.

\section{Figura 1 - Aptidão agrícola das regiões nordeste e sul goiano}
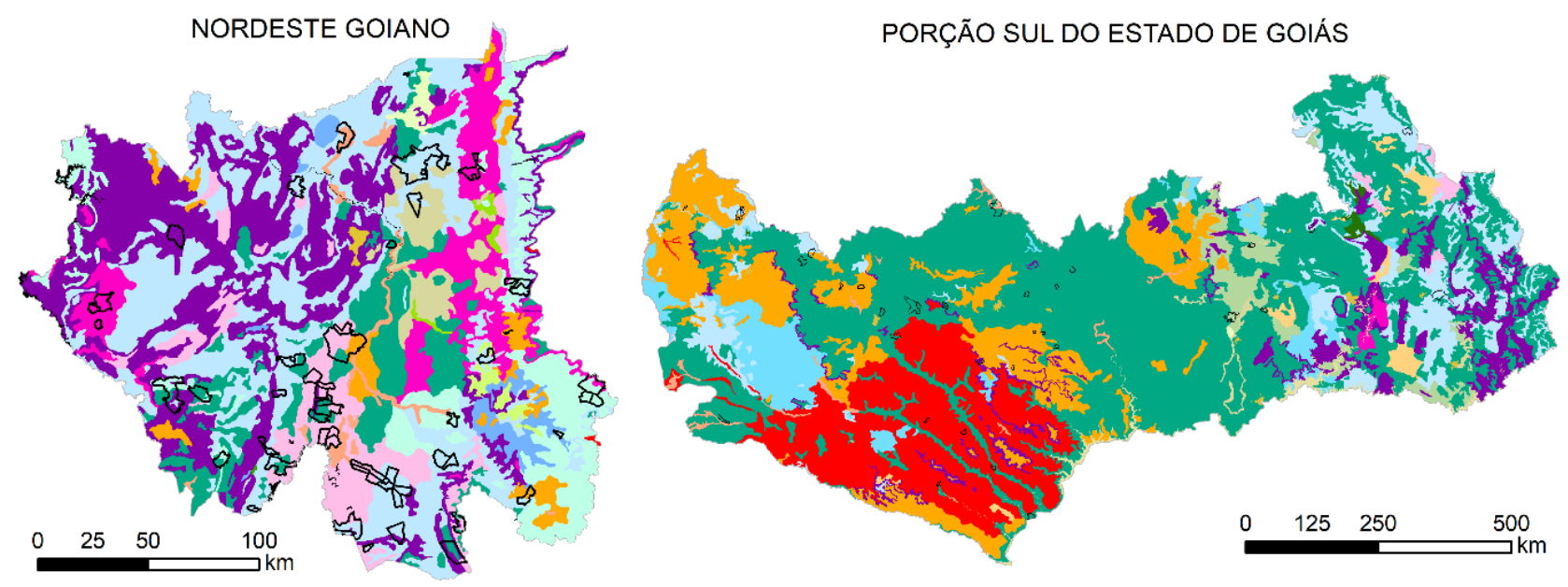

\section{Legenda}

IABC - Baa aptidãa para lavouras em todas as níveis de maneja IAB(c) - Boa aptidäo para lavouras em A e B e restrita em L

IAb - Baa aptidão para lavauras em A, regular em B e inapta em C

IAbc - Boa aptidão pera lavouras em A е геgular еп B e ᄃ

IB(c) - Aptidão BDA para lavouras em B, REGULLAR em A e INAPTA em C

IB - Ba aptidão pera lavauras em B e restrita nas demais

laB - Baa aptidãa para lavouras em B, regular em A e inapta em C

laB(c) - Aptidão regular para lavouras em A, boa em B e restrita em C

lbГ - Aptidãa regular para lalvauras na nivel de manejo B e ba em ᄃ

Zb(c)Aptidăa REGULAR em B, RESTRITA em C e INAPTA em A

Zbc - Aptidão regular para lavouras nos níveis de manejo B e ᄃ

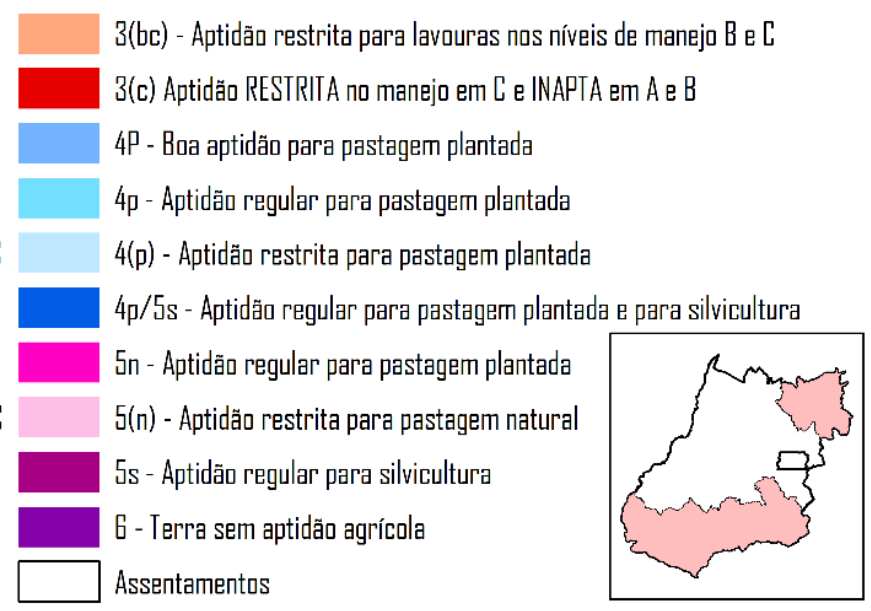

fonte: Macrozoneamento, Agroecológico e Econômico do Estado de Goiás, 2014.

base de dados: Sieg. organização: Os autores, 2019. 
nordeste goiano não se incorporou à expectativa produtiva do processo em razão da sua modesta infraestrutura e das características naturais das terras da região, de menor potencial agrícola (Figura 1). Arrais (2002), afirma que o nordeste goiano sempre esteve historicamente mais ligado ao norte de Goiás e ao Nordeste do Brasil devido seu limite com o estado da Bahia, e onde o rural caracterizava-se pela agricultura de subsistência e na pecuária extensiva. Acrescente-se que a intensificação da diferenciação regional entre o nordeste e o sul goiano ao longo do tempo deveu-se ainda ao abandono do papel de Estado de sustentador de programas de desenvolvimento, ao relegar ao setor privado o planejamento e execução do desenvolvimento, promovendo as desprezíveis taxas de crescimento do nordeste goiano que inclusive afetam a qualidade de vida da população (Castro; Xavier, 2006; Nunes, 2013) (Tabela 1).

\section{Tabela 1 - População, IDH e PIB das regiões nordeste e sul goiano}

\begin{tabular}{|l|l|l|l|l|l|}
\hline recorte espacial & $\begin{array}{l}\text { área total } \\
\left(\mathrm{km}^{2}\right)\end{array}$ & $\begin{array}{l}\text { população } \\
(2010)\end{array}$ & $\begin{array}{l}\text { IDH } \\
(2010)\end{array}$ & $\begin{array}{l}\text { PIB 2015 } \\
(\mathrm{R} \$)\end{array}$ & $\begin{array}{l}\text { participação no } \\
\text { PIB estadual (\%) }\end{array}$ \\
\hline nordeste goiano & $38.726 \mathrm{~km}^{2}$ & 186.378 & 0,647 & 2.382 .845 & $1,37 \%$ \\
\hline sul goiano & $111.752 \mathrm{~km}^{2}$ & 1.345 .413 & 0,708 & 49.781 .870 & $28,6 \%$ \\
\hline
\end{tabular}

fonte: IMB ([s.d.]).

Paralelamente à pobreza da região nordeste, pode-se constatar uma riqueza ambiental/cultural que the confere uma "contraditória qualificação", por não se haver incorporado à fronteira agrícola à custa de desmatamento intensivo e assim apresentar atualmente uma das maiores áreas contínuas de cerrado nativo do estado (Carvalho, 2004) (Figura 2). Por outro lado, Santos e Castro (2016) constataram que justamente o nordeste concentra um maior número de PA e de maior dimensão do que o sul goiano (Figura 2).

Tal constatação pode ser explicada, também pela intensificação da consolidação de uma estrutura fundiária conservadora e concentrada com raízes históricas (Pessoa, J., 1997; Silva, 2003), favorecida pelos incentivos fiscais, o preço da terra, as extensas áreas mecanizáveis da Chapas e Chapadões aplainados, o acesso às modernas tecnologias de produção em grande escala. Em consequência, os latifúndios ganharam espaço, sem que houvesse, em paralelo, nenhuma política voltada a evitar a expulsão dos pequenos produtores do campo e a elevação do processo migratório campo-cidade (Arrais et al., 2010; Calaça; Dias, 2010). Isso também explicaria a preferência do novo modelo pelo nordeste goiano para a implantação dos PA mais numerosos, beneficiando um maior número de famílias com PA maiores, mas em terras de menor aptidão agrícola (Santos, 2018) (Figuras 1 e 2). 


\section{Figura 2 - Uso e cobertura do solo e assentamentos rurais no nordeste e sul goiano}

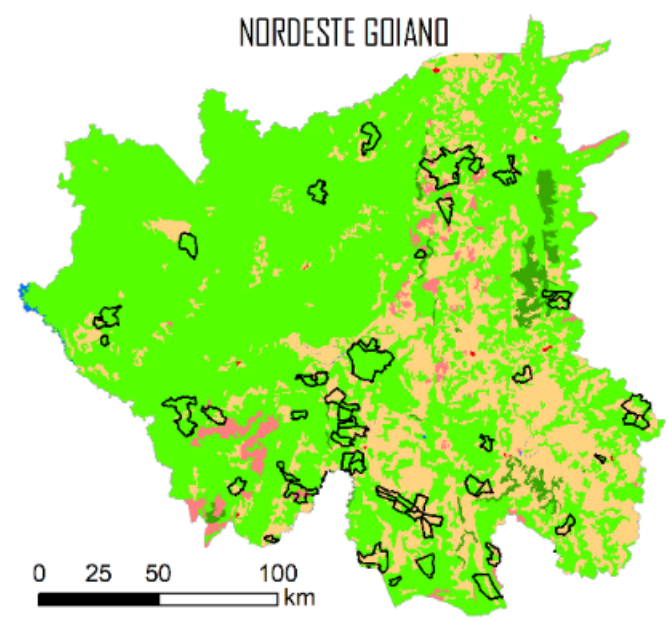

Legenda

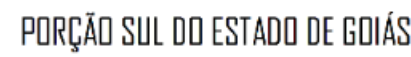
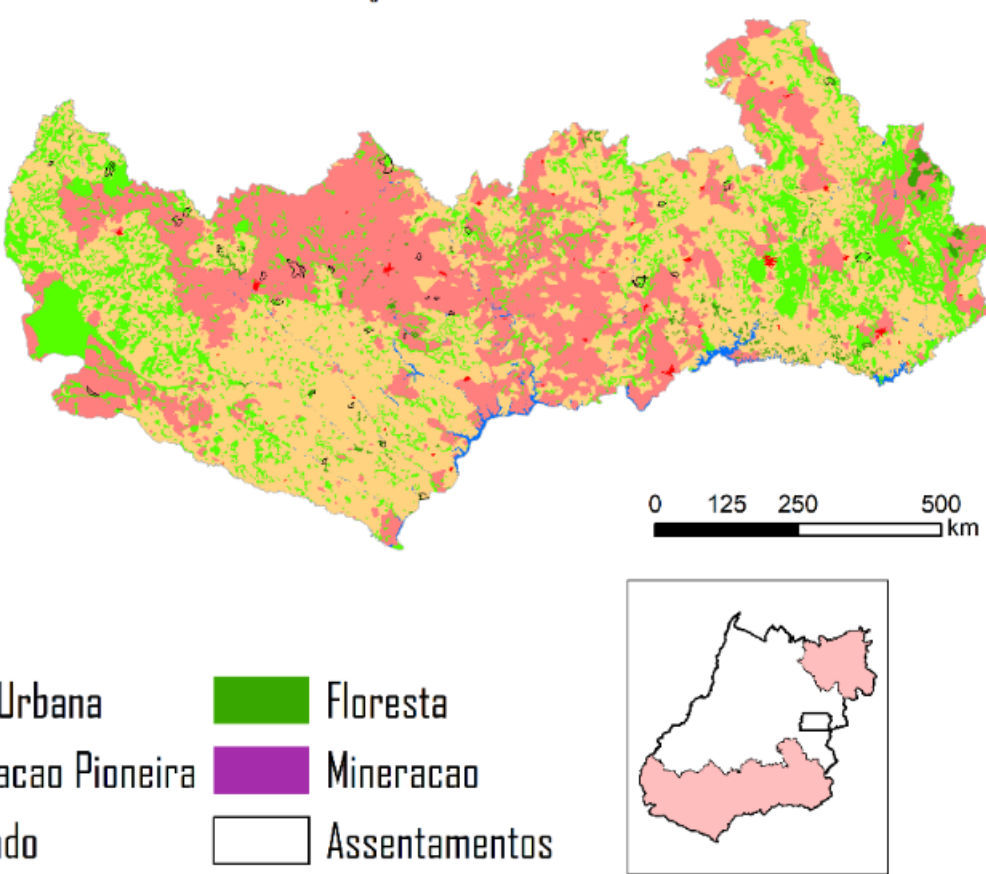

fonte: Ministério do Meio Ambiente, 2013. organização: Os autores, 2019.

As ações de reforma agrária em Goiás ocorreram mais tarde. $\bigcirc$ primeiro projeto de assentamento data de 1986 com o PA Mosquito no município de Goiás e observando a evolução do número de PA no estado, não houve alterações na estrutura fundiária, a qual se mantém praticamente a mesma nos últimos 20 anos (Arrais, 2002; Calaça; Dias, 2010). $\bigcirc$ índice Gini corrobora a concentração fundiária, pois em 1985 já se mostrava alto $(0,766)$ e dez anos mais tarde cai apenas um pouco para 0,74 e no último Censo Agropecuário de 2006, retoma ao patamar da década de 1980 com 0,776 (IBGE, 2006).

$\bigcirc$ sul do estado tem mantido seu perfil concentrador fundiário ao se consolidar como uma área de não reforma. Nesse sentido, ao invés de as ações de desconcentração fundiária ocorrerem mais intensamente nessas áreas e com isso, cumprir os seus objetivos de promover a desconcentração, os números de assentamentos criados e de famílias assentadas mostram o quão oposto os processos de modernização da agricultura e de expansão das ações de reforma agraria tem se dado em termos espaciais. A primeira se orienta em direção da incorporação de áreas com bom a ótimo desempenho produtivo e altamente dinâmica ao sul do estado. Ao passo que a segunda tem se expandido por áreas do estado com condições e potencialidades produtivas opostas às do sul, rumo ao norte em áreas renegadas pelo agronegócio (Figura 3). 


\section{Figura 3 - Densidade dos PA e famílias assentadas em Goiás}

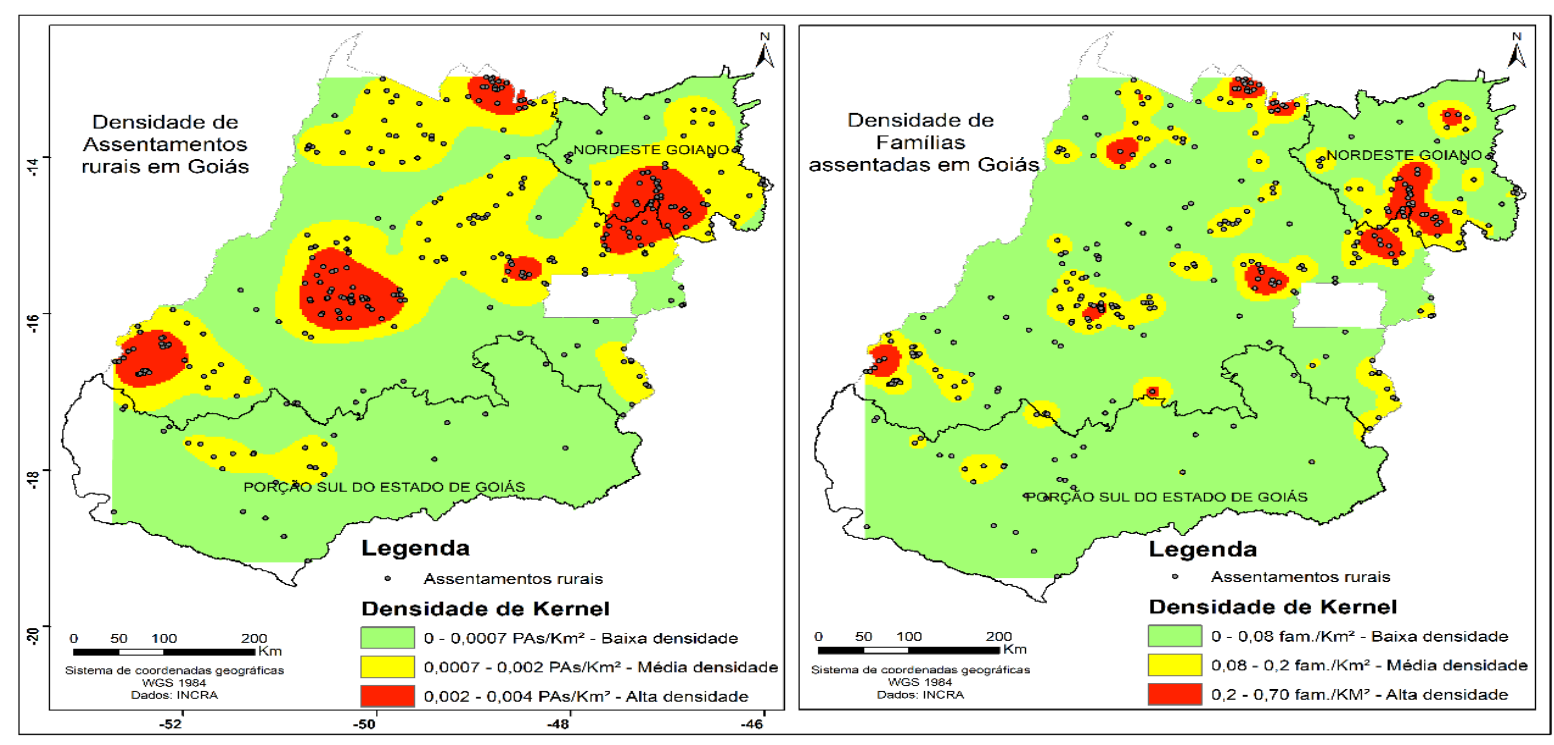

fonte: Incra ([s.d.]). organização: Os autores, 2019.

A expansão e a concentração dos assentamentos no nordeste goiano vão na contramão da teoria dos lugares centrais (Christaller, 1966) ao se concentrar nas localidades que tiveram efeito repulsivo para a expansão da fronteira agrícola. $\bigcirc$ preço das terras em Goiás, mais caro no sul e mais barato no nordeste, explicaria de certa forma o maior número de desapropriações de terras no NE e baixa no sul goiano. Prado, Miziara e Ferreira (2012) lembram que o preço da terra é definido pelas expectativas de obtenção de renda produtiva ou especulatória considerando o potencial produtivo das terras e a infraestrutura disponível. Como a criação de PA na maioria dos casos ocorre via desapropriação de terras improdutivas pelo Incra, o preço baixo das terras no nordeste goiano, reduz os custos do Incra com as desapropriações e aumenta seu número relativo, contribuindo para a inviabilização parcial ou total do desenvolvimento dos PA da região, considerando as limitações produtivas inerentes dos terrenos e a desarticulação com vias de escoamento produtivo e de centros consumidores. Assim, a verificação dessa situação, no entanto, demanda uma avaliação dos aspectos ligados ao desenvolvimento sustentável em assentamentos rurais, como ora se propõe.

\section{Metodologia}

A metodologia para a análise da sustentabilidade dos PA do nordeste e sul goianos se desenvolveu em etapas, como a seguir.

\section{Seleção de PA regionalmente representativos}

Os 57 PA do NE goiano e os 36 do sul goiano foram analisados estatisticamente como conjuntos amostrais individuais para seleção de PA representativos. $\bigcirc$ tratamento estatístico considerou cinco variáveis: aptidão agrícola, declividade, módulo fiscal do assentamento e número de familias assentadas e uso e cobertura da terra. Os valores dos quatro primeiros foram extraídos de Santos e Castro (2016) e os do uso e cobertura da terra foram extraídos do TerraClass (Brasil, 2015). A seleção baseou-se na Análise dos Componentes Principais, ACP (Pearson, 1901), um procedimento matemático-estatístico de análise multivariada, a qual facilita a identificação de relações não percebidas de imediato num dado conjunto amostral (Smith, 2002). 
resultado da ACP indicou dez assentamentos representativos do conjunto amostral original do nordeste e nove no sul goiano. Entre os regionalmente representativos, aplicou-se uma segunda ACP visando refinar a seleção e obter um par de PA (um no sul e outro no nordeste goiano). Nessa etapa, verificou-se que a qualidade da comparação estaria condicionada à seleção de PA que apresentassem algumas características em comum, como ano de criação, dimensão e características morfopedológicas (solo e relevo) para verificar o impacto sobre a sustentabilidade, mesmo se tratando de dois conjuntos regionais bem díspares. Aplicada a técnica descrita, os PA selecionados para o estudo comparado foram o PA Boa Esperança, no sul goiano, e o PA Paraná, no nordeste goiano (Figura 4).

\section{Avaliação comparada da sustentabilidade}

conceito de desenvolvimento sustentável aqui adotado partiu da ideia de pluriatividade ligada ao desenvolvimento de áreas rurais (Anjos, 2003). Segundo o autor, a pluriatividade identifica critérios para valorar os espaços rurais e redefinir sua função e o status da agricultura nesse processo, com destaque para "a importância das atividades agrícolas para o equilibrio territorial e o dinamismo das zonas rurais, assim como para a preservação dos recursos naturais que, simultaneamente, passam a ocupar o primeiro plano na definição de novas políticas agrárias" (Anjos, 2003, p. 16). Uma das formas de alcançar esse objetivo é a partir de uma perspectiva de desenvolvimento sustentável embasado no equilibrio entre aspectos sociais, econômicos e ambientais.

\section{Figura 4 - Localização do PA Paraná (à esquerda) e do PA Boa Esperança (à direita)}

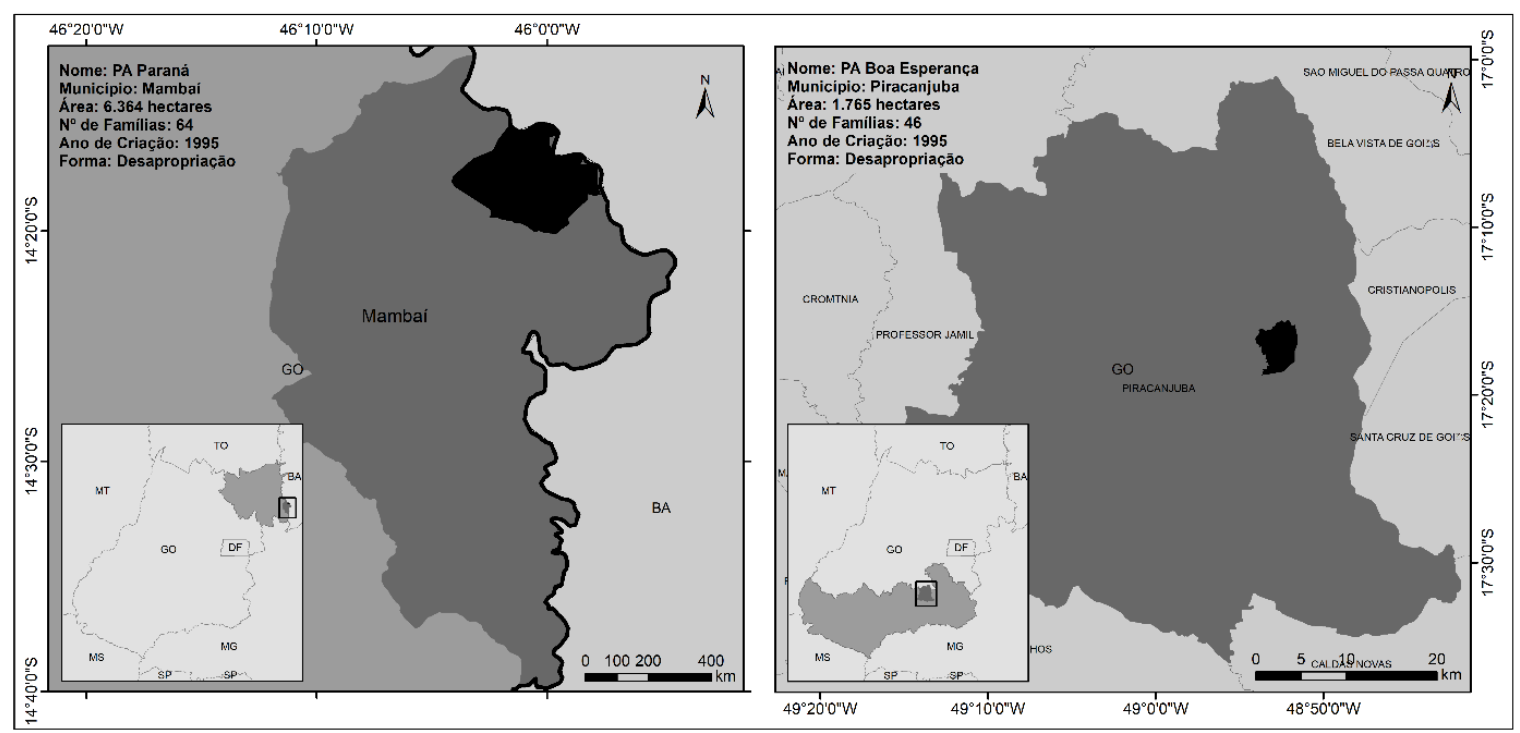

fonte: Incra ([s.d.]) e IBGE ([s.d.]). organização: Os autores, 2019.

A metodologia proposta por Pérez-Soba et al. (2008), aqui adotada, se baseia na avaliação das FUT, ou seja, dos papéis e consequências em uma dada região ou localidade em estreita relação com o uso das terras praticado. As funções são agrupadas como indicadores de três dimensões - econômica, social e ambiental -, sendo as mais relevantes, às quais se atribuem notas de 0 a 10 e que inter-relacionadas determinam a sustentabilidade. A adoção dessa 
proposta metodológica deve-se: (a) à possibilidade de diagnóstico relativamente rápido, (b) à interlocução fácil entre os as dimensões da sustentabilidade e os respectivos indicadores, (c) à flexibilidade e à adequação ao tema trabalhado e (d) à possibilidade de os resultados obtidos subsidiarem a elaboração de planos e projetos mais adequados à realidade. As fontes de dados são variadas e cada FUT contempla um rol de indicadores de sustentabilidade selecionados conforme o tema e a finalidade do estudo. $\bigcirc$ Quadro 1 expõe os 16 indicadores escolhidos, o procedimento adotado para compor a nota do indicador, bem como a fonte dos dados.

\section{Quadro 1 - Dimensões da sustentabilidade, FUT, indicadores de avalia- ção e respectivas fontes dos dados}

\begin{tabular}{|c|c|c|c|}
\hline FUT & indicadores & procedimento & fonte \\
\hline \multirow{5}{*}{ 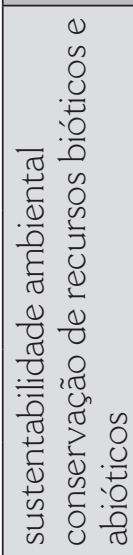 } & $\begin{array}{l}\text { 1. área de preservação } \\
\text { permanente (APP) }\end{array}$ & considerou-se a \% de APP preservada & $\begin{array}{l}\text { cadastro ambiental } \\
\text { rural (CAR) }\end{array}$ \\
\hline & $\begin{array}{l}\text { 2. reserva legal }(R L) \\
\text { preservada }\end{array}$ & considerou-se a \% de RL preservada & CAR \\
\hline & $\begin{array}{l}\text { 3. suscetibilidade à } \\
\text { erosão laminar }\end{array}$ & $\begin{array}{l}\text { considerou-se a \% de terras que apresentam } \\
\text { baixo e/ou nulo potencial para perda de solos } \\
\text { por erosão laminar }\end{array}$ & $\begin{array}{l}\text { mapa de suscetibilidade } \\
\text { à erosão laminar }\end{array}$ \\
\hline & $\begin{array}{l}\text { 4. potencial de perda } \\
\text { de solo }\end{array}$ & $\begin{array}{l}\text { a avaliação do indicador levou em conta } \\
\text { somente a \% terras com baixo potencial }\end{array}$ & $\begin{array}{l}\text { mapa de potencial à } \\
\text { erosão laminar }\end{array}$ \\
\hline & $\begin{array}{l}\text { 5. adequabilidade de } \\
\text { uso das terras }\end{array}$ & $\%$ de terras com uso adequado & $\begin{array}{l}\text { mapa de adequabilidade } \\
\text { de uso }\end{array}$ \\
\hline \multirow{6}{*}{ 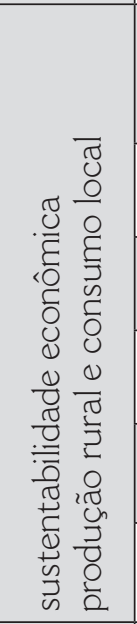 } & $\begin{array}{l}\text { 6. potencial produtivo } \\
\text { das terras }\end{array}$ & $\begin{array}{l}\text { soma das terras com potencial produtivo para } \\
\text { usos convencionais e limitações leves e de fácil } \\
\text { reversão }\end{array}$ & $\begin{array}{l}\text { mapa de capacidade de } \\
\text { uso das terras }\end{array}$ \\
\hline & $\begin{array}{l}\text { 7. área cultivada (ha) } \\
\text { efetiva }\end{array}$ & $\begin{array}{l}\text { \% área com potencial / \% área efetivamente } \\
\text { ocupada }\end{array}$ & $\begin{array}{l}\text { mapa de uso e } \\
\text { cobertura do solo }\end{array}$ \\
\hline & $\begin{array}{l}\text { 8. área de pasto (ha) } \\
\text { efetiva }\end{array}$ & $\begin{array}{l}\text { \% área com potencial / \% área efetivamente } \\
\text { ocupada }\end{array}$ & $\begin{array}{l}\text { mapa de uso e } \\
\text { cobertura do solo } \\
\end{array}$ \\
\hline & $\begin{array}{l}\text { 9. diversificação } \\
\text { produtiva }\end{array}$ & $\begin{array}{l}\text { atividades econômicas predominantes em cada } \\
\text { lote }\end{array}$ & $\begin{array}{l}\text { mapa de uso e } \\
\text { cobertura do solo }\end{array}$ \\
\hline & $\begin{array}{l}\text { 10. acesso a linhas } \\
\text { crédito }\end{array}$ & $\begin{array}{l}\text { considerou-se a \% de familias que relataram } \\
\text { acessar crédito rural recentemente }\end{array}$ & questionários \\
\hline & $\begin{array}{l}\text { 11. assistência técnica } \\
\text { continuada }\end{array}$ & $\begin{array}{l}\text { considerou-se a \% de famílias que relataram } \\
\text { acessar assistência técnica continuada }\end{array}$ & questionários \\
\hline \multirow{5}{*}{ 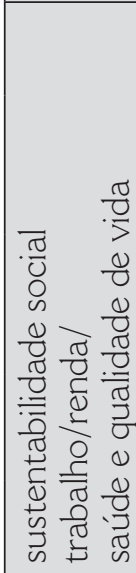 } & 13. emprego/ocupação & $\begin{array}{l}\text { \% das familias que declararam que os seus } \\
\text { membros estão ocupados dentro da parcela }\end{array}$ & questionários \\
\hline & 12. renda & $\begin{array}{l}\text { \% de famílias que declararam que a maior parte } \\
\text { da renda advém das atividades econômicas } \\
\text { desenvolvidas dentro de sua parcela }\end{array}$ & questionários \\
\hline & $\begin{array}{l}\text { 14. abastecimento } \\
\text { adequado de água }\end{array}$ & $\begin{array}{l}\text { considerou-se a \% de famílias que relataram } \\
\text { acessar água em níveis e qualidade suficiente p/ } \\
\text { o consumo próprio e produção }\end{array}$ & questionários \\
\hline & $\begin{array}{l}\text { 15. acesso a serviços } \\
\text { básicos }\end{array}$ & considerou-se a o nível de satisfação/insatisfação & questionários \\
\hline & $\begin{array}{l}\text { 16. cooperativismo e } \\
\text { associativismo rural }\end{array}$ & $\begin{array}{l}\text { \% das familias que declararam participar da } \\
\text { associação do assentamento }\end{array}$ & que \\
\hline
\end{tabular}


Os indicadores selecionados segundo o princípio de relevância para a temática dos assentamentos rurais foram qualitativos e quantitativos, além de multifuncionais, que permitiram demonstrar de modo simples, claro e objetivo a situação de sustentabilidade atual dos PA focados. Entre os 16 indicadores selecionados (Quadro 1), cinco são sociais, cinco ambientais e seis econômicos, todos avaliados na mesma escala de pontos, de 0 a 10, inclusive os indicadores qualitativos, de modo a padronizar e facilitar a contagem. Quanto mais distante de 0 e próximo de 10 for o valor do indicador, melhor seu desempenho. A articulação entre as dimensões da sustentabilidade, as FUT e os indicadores de sustentabilidade compôs o sistema de avaliação do desenvolvimento sustentável do PA, nos referidos três níveis ilustrado na figura 5.

\section{Figura 5 - Sistema de avaliação do desenvolvimento sustentável em PA}

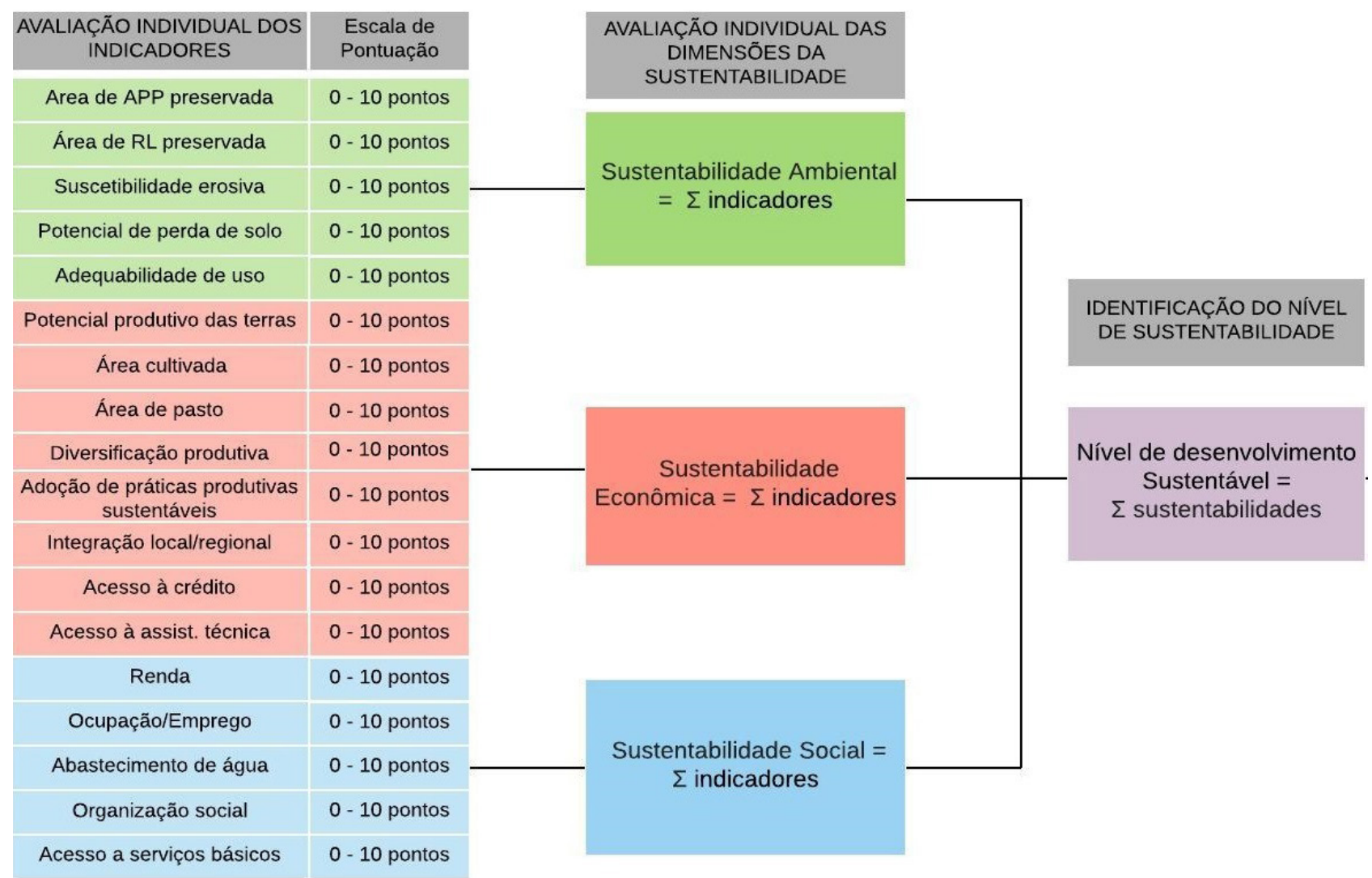

elaboração: Os autores, 2019.

A integração das dimensões da sustentabilidade, última etapa da avaliação do desenvolvimento sustentável, baseou-se na soma da pontuação das três dimensões avaliadas individualmente (ambiental, econômica e social), resultando na avaliação da situação atual do assentamento quanto ao seu nível de desenvolvimento sustentável. A escala de pontuação variou de 0 a 160 para os 16 indicadores. Os valores foram agrupados em cinco classes (Quadro 2), observadas a praticidade e a objetividade do sistema de classificação, sendo que cada uma delas demonstra a situação atual do PA no que se refere ao seu desenvolvimento sustentável. 


\section{Quadro 2 - Nível de sustentabilidade}

\begin{tabular}{|l|l|}
\hline pontos & nível de sustentabilidade \\
\hline $0-60$ & não sustentável \\
\hline $60,1-85$ & pouco sustentável \\
\hline $86-110$ & moderadamente sustentável \\
\hline $111-135$ & altamente sustentável \\
\hline $136-160$ & totalmente sustentável \\
\hline
\end{tabular}

Convém assinalar que após análise dos dados disponíveis nas diversas fontes, bem como os elaborados, executou-se trabalho de campo nos PA selecionados para validação dos mapas produzidos e consultar as famílias por meio de entrevistas semiestruturadas, objetivando analisar sua situação socioeconômica e seu grau de satisfação. Foram entrevistadas seis famílias no PA Boa Esperança e cinco no PA Paraná que se disponibilizaram a colaborar com a pesquisa. As questões foram relativas a: número de moradores no lote, profissão/ocupação atual, tempo de moradia, forma de obtenção da terra, procedência, envolvimento com movimentos sociais antes e depois de assentado, conhecimento de agricultura/pecuária prévios. Os resultados foram tabulados, interpretados e incorporados ao texto.

\section{A sustentabilidade nos assentamentos rurais do nordeste e do sul goiano Sustentabilidade econômica}

No PA Boa Esperança, as terras com potencial para cultivo somam 970 ha e estão bem distribuídas, contemplando a maioria dos lotes. Nessas terras ocorrem latossolos em relevo plano e suave ondulado de alto desempenho produtivo, quando corrigida acidez e repostas as bases nutrientes. No PA Paraná, as terras cultiváveis somam 850 ha, mas estão restritas a 19 dos 70 lotes do PA. Esses lotes privilegiados se situam na chapada correspondendo a apenas 13\% de todo o terreno do PA. Seu potencial produtivo predominante indica terras inviáveis para um uso nos mesmos moldes do PA do sul goiano, ou mesmos nos moldes permitidos nos 19 lotes privilegiados, considerando suas limitações naturais, por exemplo, solos rasos e inconsolidados, que se adequam mais à pecuária extensiva no limite permitido pela capacidade de uso das terras e, em casos mais extremos, restringem totalmente o uso. 


\section{Tabela 2 - PA Paraná e PA Boa Esperança: comparativo de potencial pro- dutivo das terras e uso efetivo das terras}

\begin{tabular}{|c|c|c|c|c|c|}
\hline & \multirow{2}{*}{$\begin{array}{l}\text { terras indicadas preferen- } \\
\text { cialmente para: }\end{array}$} & \multicolumn{2}{|c|}{$\begin{array}{l}\text { PA Paraná } \\
\text { (nordeste goiano) }\end{array}$} & \multicolumn{2}{|c|}{$\begin{array}{l}\text { PA Boa Esperança } \\
\text { (sul goiano) }\end{array}$} \\
\hline & & área (ha) & área (\%) & área (ha) & área (\%) \\
\hline \multirow{4}{*}{$\begin{array}{l}\text { potencial } \\
\text { produtivo } \\
\text { das terras }\end{array}$} & agricultura & 850 & $13,5 \%$ & 969,1 & 55 \\
\hline & pastagem & 315,4 & $5,0 \%$ & 585,7 & 33 \\
\hline & $\begin{array}{l}\text { extremamente restritiva ao uso } \\
\text { ou sem potencial produtivo }\end{array}$ & $5.125,2$ & $81,4 \%$ & 204,6 & 12 \\
\hline & área total & $6.290,7$ & 100 & $1.759,4$ & 100 \\
\hline \multirow{5}{*}{ agricultura } & $\begin{array}{l}\text { área total indicada preferencial- } \\
\text { mente para agricultura }\end{array}$ & \multicolumn{2}{|l|}{850 ha* } & \multicolumn{2}{|l|}{969,1 ha } \\
\hline & status & área (ha) & área (\%) & área (ha) & área (\%) \\
\hline & $\begin{array}{l}\text { cultivos em área indicada prefe- } \\
\text { rencialmente } \mathrm{p} / \text { agricultura }\end{array}$ & - & - & 52,5 & 95,6 \\
\hline & $\begin{array}{l}\text { cultivos em área indicada prefe- } \\
\text { rencialmente } \mathrm{p} / \text { outros usos }\end{array}$ & - & - & 3,2 & 4,4 \\
\hline & área total utilizada & \multicolumn{2}{|l|}{-} & \multicolumn{2}{|l|}{54,9 ha } \\
\hline \multirow{5}{*}{ pastagem } & $\begin{array}{l}\text { área indicada preferencialmente } \\
\mathrm{p} / \text { pastagem }\end{array}$ & \multicolumn{2}{|l|}{315,4 ha } & \multicolumn{2}{|l|}{585,7 ha } \\
\hline & status & área (ha) & área (\%) & área (ha) & área (\%) \\
\hline & $\begin{array}{l}\text { pastagem em área preferencial- } \\
\text { mente indicada para pastagem }\end{array}$ & 0,2 & 0,05 & 522,8 & 42 \\
\hline & $\begin{array}{l}\text { pastagem em área indicada pre- } \\
\text { ferencialmente } \mathrm{p} / \text { outros usos }\end{array}$ & 328,1 & 99,95 & 595 & 58 \\
\hline & área total utilizada & \multicolumn{2}{|l|}{328,3 ha } & \multicolumn{2}{|l|}{ 1.017,8 ha } \\
\hline
\end{tabular}

* Terras disponíveis para apenas 19 dos 70 lotes.

legenda: $(-)=$ dado inexistente fonte: Levantamento da Capacidade de Uso das Terras (Figuras 40 e 41) e de uso de cobertura do solo (Figuras 43 e 44). Imagem RapidEye. organização: Os autores, 2019.

Em ambos os PA, notou-se subutilização de terras, mas com áreas diferentes. No Boa Esperança, o subaproveitamento das terras cultiváveis decorre da integração à cadeia do leite. Assim, a maioria das famílias se dedica exclusivamente à pecuária extensiva. Em função disso, apenas 54,9 ha $(5,65 \%)$ do potencial de terras cultiváveis são efetivamente utilizados por culturas que atendem principalmente à subsistência. No PA Paraná, em 18 dos 19 lotes que apresentam terras com potencial agrícola, não há aproveitamento do potencial produtivo nem mesmo para a subsistência. Entre as causas, verificou-se que existem problemas de natureza socioeconômica que dificultam a manutenção das famílias em suas parcelas, como problemas de acesso contínuo à água, falta de transporte escolar e distância da cidade, além de limitação técnica e baixa capacidade das famílias de acessar crédito, assistência técnica ou programas do governo de incentivo à produção de alimentos, o que desencoraja e obsta a maior utilização das terras. 
As campanhas de campo confirmaram a baixa diversificação produtiva já identificada no mapeamento de uso e cobertura do solo em ambos os PA. Em cinco dos seis lotes visitados, as famílias se dedicam exclusivamente à pecuária extensiva e, em menor intensidade, à criação de animais de pequeno porte, tendo sua renda parcial ou totalmente dependente da primeira. Em apenas um lote visitado os cultivos diversos são a atividade principal.

No PA Paraná, as atividades voltadas à comercialização inexistem e afetam negativamente a renda e a ocupação das famílias, tornando-as dependentes de atividades externas, auxílios e aposentadorias. As atividades voltadas à subsistência se resumem à criação de aves e à presença de pequenas hortas em alguns dos lotes visitados, os quais atendem a subsistência. A diversificação produtiva, portanto, é praticamente nula considerando os poucos itens produzidos, a falta de comercialização e a área pequena área efetivamente ocupada pelas atividades observadas.

Quanto à oferta de crédito, no PA Boa Esperança no sul goiano, verificou-se nas campanhas de campo e conversas com as famílias, que elas conseguem acessar crédito via Incra e até mesmo apresentam condição de adquirir por conta própria. Um dos moradores que sobrevive da produção de hortaliças, legumes e frutas tem minitrator e um caminhão adquirido recentemente, por conta própria, para o transporte e a distribuição da produção. As famílias que vivem da venda do leite possuem resfriador com capacidade de armazenagem de até 500 L também adquirido por conta própria. Os recursos financeiros disponíveis geralmente são empregados em sua totalidade na produção, mas seus resultados poderiam ser ampliados, caso houvesse amparo e acompanhamento técnico regular. Acerca do crédito fornecido pelo Incra durante as fases iniciais do PA Paraná, foi relatado que o valor recebido ficou aquém do prometido e que ainda por cima foi gasto sem nenhum acompanhamento técnico, não produzindo retorno produtivo imediato e nem mesmo a médio ou longo prazo.

Sobre a assistência técnica, no PA Boa Esperança, dos seis entrevistados, quatro disseram que a recebiam, mas a caracterizaram como insuficiente e dois afirmaram nem a acessaram recentemente. Entre os que disseram receber assistência técnica mensalmente do Incra, com a visita de duas engenheiras agrônomas, foi relatado que o atendimento foi recentemente descontinuado. No PA Paraná, a falta de assistência técnica adequada e contínua é fato destacado pelos moradores mais antigos do assentamento. Segundos eles, nem mesmo nas fases iniciais houve acompanhamento das famílias para qualquer tipo de projeto de desenvolvimento produtivo, mostrando mais uma vez que a frágil situação do PA do nordeste goiano que indica a falta de observância dos critérios de seleção de terras, passa pela desatenção das ações necessárias à consolidação de sistemas produtivos que não precisam ser necessariamente de natureza agropecuária e impactam diretamente de forma negativa a renda, o emprego e a qualidade de vida dos assentados.

A comparação entre o desempenho de cada um dos indicadores econômicos nos PA estudados consta na Tabela 3. 


\section{Tabela 3 - Avaliação comparada da sustentabilidade}

\begin{tabular}{|c|c|c|c|}
\hline dimensão - FUT & indicador & $\begin{array}{l}\text { PA Boa Espe- } \\
\text { rança } \\
\text { sul goiano } \\
\end{array}$ & $\begin{array}{l}\text { PA Paraná nor- } \\
\text { deste goiano }\end{array}$ \\
\hline \multirow{6}{*}{$\begin{array}{l}\text { econômica: produ- } \\
\text { ção rural e consumo } \\
\text { local }\end{array}$} & potencial produtivo das terras & 7,8 & 1,8 \\
\hline & área cultivada & 0,5 & 0 \\
\hline & área de pasto & 8,9 & 0 \\
\hline & diversificação produtiva & 3,3 & 0 \\
\hline & crédito Rural & 5,0 & 0 \\
\hline & assistência técnica & 3,3 & 0 \\
\hline
\end{tabular}

Como mostra a Tabela 3, no PA do nordeste goiano apenas um indicador registrou ponto indicando que suas terras não desempenham satisfatoriamente nenhuma função econômica, haja vista as limitações técnicas e ambientais identificadas. A situação é tão precária, que chega a comprometer outras funções atrelas ao uso da terra, a exemplo de funções sociais como a renda e emprego, intensificando as chances de abandono das parcelas, a qual já é elevada, conforme relatos das famílias entrevistadas. Já no PA do sul do estado, a sustentabilidade econômica é moderadamente assegurada, principalmente em função da dependência econômica da venda do leite que garante renda, mas afeta negativamente a diversificação produtiva. As terras desempenham função econômica, que poderia ser melhorada caso o uso se aproximasse da capacidade, observadas as configurações econômicas e os circuitos de comercializações locais e regionais.

\section{Sustentabilidade social}

No PA Boa Esperança, as entrevistas mostram que em os membros adultos da família se ocupam de atividades ligadas à produção, dentro de suas parcelas e se autodeclarando produtores rurais. A renda em decorrência é, no todo ou maior parte, dependente da produção interna. O ótimo comportamento dos indicadores renda e emprego são impulsionados pelas condições produtivas das terras que favorecem tanto a agricultura quanto a pecuária de alto desempenho e pela possibilidade de integração econômica regional em vista da maior dinamicidade resultante da presença de centros consumidores e vias de escoamento da produção.

A presença da Cooperativa Agropecuária Mista de Piracanjuba (Coapil), da qual a maior parte dos entrevistados se declarara associados, desempenha uma importante função garantidora da renda e emprego das famílias do PA Boa Esperança, pois toda a produção de leite é comprada pela cooperativa. $O$ leite é vendido a um preço que costuma ficar entre $R \$ 1,00$ e R \$1,50. Dependendo da família a produção (1/dia) diária varia de 80 a 250 l/dia e, segundo relatado, atende a demanda das famílias, favorecendo a fixação dos beneficiários às suas terras.

No PA Paraná, notou-se o oposto entre os entrevistados, pois nenhum dos membros adultos encontra-se devidamente ocupados nas suas parcelas explorando-as economicamente. A renda mensal é totalmente dependente de auxílios e/ou aposentadorias e em menor parte, de atividades externas. Essas atividades são esporádicas e a renda decorrente não atende às necessidades básicas das famílias ou atendem moderadamente, gerando insegurança e insatis- 
fação financeira, contribuindo para o aumento as chances de abandono do lote. Essa situação segundo os moradores mais antigos ocorre com bastante recorrência e atinge, atualmente, mais da metade das parcelas do PA.

Quanto ao abastecimento de água, no PA Paraná, o parcelamento das terras gerou uma diferença interna entre os lotes, o que afetou o desempenho do indicador rebaixando-o. Em 51 dos 70 lotes situados na porção menos elevada do PA a água atende perfeitamente as demandas de consumo e produção. No entanto, em 19 lotes, situados na chapada, não há rios ou córregos que permitam a captação direta. $\bigcirc$ estabelecimento de famílias foi por muito tempo impedido nessa área, pois não havia a infraestrutura para captação de água, o qual somente ocorreu mais tarde, quando a infraestrutura foi construída para o bombeamento de água dos lotes à jusante. Hoje, após o parcelamento e construção da estrutura de captação de água, há uma dependência da infraestrutura de captação instalada nos lotes à jusante, gerando insegurança quanto ao acesso regular ao recurso. No PA Boa Esperança, não se registrou nenhuma queixa das familias quanto ao acesso, a regularidade ou a qualidade do recurso.

No PA Boa Esperança, todas as famílias relataram que o lixo produzido é queimado internamente. Equipes de saúde visitam o PA uma vez por mês. Consultas médicas com especialistas são realizadas no perímetro urbano do município de Piracanjuba. As crianças estão matriculadas no município de Piracanjuba e a prefeitura oferece transporte de ida e volta. Todas as parcelas visitadas estão conectadas à rede elétrica. A nota atribuída ao indicador Acesso a serviços básicos foi 5,1, valor intermediário que mostra que, exceto pela coleta de lixo e pela falta de instrumentos de lazer em cultura - não fornecidos pela prefeitura como todos os demais -, eles geram a satisfação das familias, embora moderadamente.

No PA Paraná, verificou-se que o acesso à energia elétrica é o único subindicador atendido plenamente. Quanto ao acesso a serviços de saúde foi relatado que, a cada dois meses, uma equipe de saúde da prefeitura visita o assentamento na casa de uma das moradoras onde ocorre o atendimento. Consultas a especialistas, exames, tratamentos mais intensivo ou exigência de acompanhamento médico regular é oferecido no sistema de saúde do município de Mambaí-GO que fica a cerca de 25 km do PA. Em todos os casos, notou-se a percepção de que $\mathrm{o}$ atendimento precisa ser melhorado, em termos de especialidades médicas e em termos de regularidades das visitas. Notou-se que dentro do assentamento não funciona nenhuma escola. As crianças têm aula no município de Mambaí. $\bigcirc$ transporte é da prefeitura, mas não atende a totalidade das parcelas.

No PA Paraná, a situação é deficitária e prejudicada pela falta de organização interna das famílias que dificulta a interlocução e o atendimento das demandas das famílias junto à prefeitura e ao Incra. $\bigcirc$ PA Boa Esperança conta com uma associação devidamente registrada e com instalações, no entanto, atualmente está pouco ativa. Notou-se que apesar da associação existir, nenhuma ação prática vem sendo desempenhada a ponto de motivar o engajamento social das famílias. Verificou-se insatisfação quanto à gestão atual e até mesmo, certa desconfiança a respeito de práticas de associativismo internas por conta de experiências anteriores infelizes. A adesão é obtida externamente a partir de associação a cooperativas e ao sindicato de produtores rurais do município de Piracanjuba. A associação mais presente é a Coapil, que garante a compra de toda a produção de leite e assegura renda e estabilidade às famílias. 
A Tabela 4 expõe os valores obtidos para cada um dos cinco indicadores sociais avaliados em ambos os PA.

\section{Tabela 4 - Avaliação comparada da sustentabilidade}

\begin{tabular}{|c|c|c|c|}
\hline dimensão - FUT & $\begin{array}{l}\text { indicador de sustentabili- } \\
\text { dade }\end{array}$ & $\begin{array}{l}\text { PA Boa Esperan- } \\
\text { ça } \\
\text { sul goiano }\end{array}$ & $\begin{array}{l}\text { PA Paraná nor- } \\
\text { deste goiano }\end{array}$ \\
\hline \multirow{5}{*}{$\begin{array}{l}\text { social: trabalho, } \\
\text { renda e qualidade } \\
\text { de vida }\end{array}$} & emprego/ocupação & 10 & 0 \\
\hline & renda & 6,6 & 0 \\
\hline & acesso à água & 10 & 3,3 \\
\hline & acesso a serviços básicos & 5,1 & 3,4 \\
\hline & organização interna & 2,5 & 0 \\
\hline
\end{tabular}

No PA do sul, verificou-se que a sustentabilidade social é altamente assegurada, indicando que a terra tem uma importante função social. Apenas um indicador apresenta valor baixo (organização interna) e um segundo alcançou valor médio (acesso a serviços básicos). A composição da renda depende totalmente das atividades econômicas realizadas dentro das parcelas, excluindo-se por completo a dependência de trabalho externo, favorecendo a fixação da familia à terra. Não há problema de acesso à água para consumo próprio ou para a demanda produtiva. $\bigcirc$ acesso a serviços básicos ocorre e supre as necessidades, mas poderia ser melhorado.

No PA Paraná, a sustentabilidade social é totalmente comprometida. A terra não desempenha nenhuma função social. A renda das familias não resulta do aproveitamento produtivo das parcelas, mas exclusivamente de aposentadorias e auxílios e em menor parte de atividades realizadas fora do PA. Os níveis de desocupação e desemprego são elevados, gerando insegurança. A desarticulação social entre as famílias é evidente. A insatisfação com os serviços sociais básicos é recorrente, comprometendo até mesmo a qualidade de vida dos assentados. Por fim, todos os indicadores sociais avaliados induzem o abandono de parcelas, como constatado.

\section{Sustentabilidade ambiental}

As semelhanças entre os PA ficaram restritas aos aspectos ambientais, principalmente, aqueles ligados à preservação de áreas de interesse ambiental protegidas por leis. Ao comparar a área de APP, por exemplo, verificou-se que os dois PA cumprem as metragens mínimas estabelecidas para cada modalidade (Tabela 5). As áreas que necessitam de recomposição da vegetação nativa em área de APP são localizadas e reduzidas. Especificamente no assentamento Paraná, a área de APP a ser recomposta equivale a 0,4\% e no PA Boa Esperança essa área é um pouco maior, sendo 2,3\% de toda a área destinada à preservação. Em ambos os PA, as RLs estão bem situadas em áreas mais frágeis que requerem proteção. No PA Paraná, a RL compreende a área de escarpa que apresenta declive que ultrapassa os 45\% e no PA Boa Esperança a RL está situada na área do Hogback, a qual é a mais elevada e movimentada porção do terreno (Tabela 5). 


\section{Tabela 5 - PA Paraná e PA Boa Esperança: percentual de APP e RL}

preservadas

\begin{tabular}{|c|c|c|c|c|c|}
\hline & \multicolumn{2}{|c|}{$\begin{array}{l}\text { PA Paraná nordeste } \\
\text { goiano }\end{array}$} & \multicolumn{2}{|c|}{$\begin{array}{l}\text { PA Boa Esperança } \\
\text { sul goiano }\end{array}$} \\
\hline \multirow{5}{*}{$\begin{array}{l}\text { \% de área de preser- } \\
\text { vação permanente } \\
(A P P) \text { preservada }\end{array}$} & área total & 1.032 há & & 70 ha & \\
\hline & classe & área (ha) & área (\%) & área (ha) & área \% \\
\hline & área preservada & 992,6 & 96,2 & 58,8 & 84 \\
\hline & área com uso consolidado & 38 & 3,7 & 11,2 & 16 \\
\hline & área a recompor & 4,5 & 0,4 & 1,64 & 2,3 \\
\hline \multirow{5}{*}{$\begin{array}{l}\% \text { de reserva legal } \\
(\mathrm{RL}) \text { preservada }\end{array}$} & área total & \multicolumn{2}{|l|}{ 1.640,8 há } & \multicolumn{2}{|l|}{355,6 ha } \\
\hline & classe & área (ha) & área (\%) & área (ha) & área \% \\
\hline & área preservada & 1.618 & 98,6 & 354 & 99,5 \\
\hline & área com uso consolidado & 22,8 & 1,4 & 1,66 & 0,5 \\
\hline & área a recompor & - & - & - & - \\
\hline
\end{tabular}

fonte: Limites das APP e RLs: Sistema Florestal Brasileiro - Cadastro Ambiental Rural - Municípios de Mambaí e Piracanjuba. base de dados: SICAR. uso e cobertura do solo: imagem RapidEye (em 2015). organização: Os autores, 2019.

Em ambos os casos, o uso consolidado em RL é baixíssimo, ficando em 1,4\% de sua área no PA Paraná e 0,5\% no PA Boa Esperança. Desse modo, a área de vegetação nativa devidamente preservada alcança valores elevados, sendo 98,6\% da área de RL no PA Paraná e 99,5\% no PA Boa Esperança.

Ao avaliar as áreas mais afetadas pelo uso, consideraram-se dois indicadores: o potencial de erosão laminar e a superutilização de terras. A Tabela 6 compara os resultados obtidos para ambos os PA.

\section{Tabela 6 - PA Paraná e PA Boa Esperança: potencial de perda de solos por erosão laminar e discrepância de uso}

\begin{tabular}{|c|c|c|c|c|c|}
\hline & \multirow[b]{2}{*}{ classe } & \multicolumn{2}{|c|}{$\begin{array}{l}\text { PA Paraná } \\
\text { nordeste goiano }\end{array}$} & \multicolumn{2}{|c|}{$\begin{array}{l}\text { PA Boa Esperança } \\
\text { sul goiano }\end{array}$} \\
\hline & & área (ha) & área \% & área (ha) & área \% \\
\hline \multirow{3}{*}{$\begin{array}{l}\text { potencial de perda de } \\
\text { solo }\end{array}$} & alto potencial & 50,4 & 1 & 81,01 & 5 \\
\hline & médio potencial & 1487,5 & 24 & 735,74 & 42 \\
\hline & baixo potencial & $4.752,4$ & 75 & 942,8 & 53 \\
\hline \multirow[b]{2}{*}{ discrepância de uso } & situação & área (\%) & área (\%) & área (ha) & área (\%) \\
\hline & $\begin{array}{l}\text { terras } \\
\text { superutilizadas }\end{array}$ & 104,9 & 2 & 97,7 & 6 \\
\hline
\end{tabular}

No PA Paraná, as terras com alto potencial de perda de solo por erosão laminar correspondem a cerca de $1 \%$ do total de terras, enquanto no PA Boa Esperança, esse potencial atinge $5 \%$ do total. Em ambos foram identificados valores bem reduzidos de superutilização de terras, sendo que no PA Paraná, apenas $2 \%$ das terras está em tal situação e, no PA Boa Esperança, 6\%. Os números inferiores no PA Paraná, decorrem do baixo uso efetivo do solo. A Tabela 7 conjuga os valores obtidos para os indicadores ambientais nos dois assentamentos. 


\section{Tabela 7 - Avaliação comparada da sustentabilidade ambiental}

\begin{tabular}{|l|l|l|l|}
\hline \multirow{2}{*}{ dimensão - FUT } & indicador de sustentabilidade & $\begin{array}{l}\text { PA Boa } \\
\text { Esperança } \\
\text { sul goiano }\end{array}$ & $\begin{array}{l}\text { PA Paraná } \\
\text { nordeste } \\
\text { goiano }\end{array}$ \\
\hline \multirow{4}{*}{$\begin{array}{l}\text { ambiental: conservação } \\
\text { de recursos bióticos e } \\
\text { abióticos }\end{array}$} & \% área de APP preservada & 8,4 & 9,6 \\
\cline { 2 - 4 } & suscetibilidade a erosão laminar & 9,9 & 9,8 \\
\cline { 2 - 4 } & potencial de perda de solo por erosão laminar & 5,3 & 1,5 \\
\cline { 2 - 4 } & uso adequado das terras & 4,9 & 8,5 \\
\hline \multirow{2}{*}{ total } & & 32,7 & 36,9 \\
\hline
\end{tabular}

A somatória dos indicadores ambientais é elevada, 36,9 no PA Paraná e 32,7 no PA Boa Esperança, sinalizando sustentabilidade ambiental altamente assegurada. No PA Paraná, o único indicador que apresentou valores baixos foi o de suscetibilidade à erosão resultante da grande extensão de terras extremamente e muito suscetíveis à erosão laminar, que em função da incipiente utilização do solo se encontram, em sua maior parte, preservadas, contribuindo para a redução do potencial erosivo. Em ambos os casos, os valores de terras superutilizadas são baixos e as áreas de interesse ambiental estão demarcadas corretamente embora ocorram usos inadequados pontuais, porém leves e em pequena extensão. No PA Boa Esperança, três indicadores apresentaram valores médios, no entanto, não comprometem outros indicadores ou funções inerentes ao uso da terra.

\section{Identificação do nível de sustentabilidade}

Na Figura 5 são combinados os resultados obtidos para cada um dos 16 indicadores avaliados em ambos os assentamentos estudados que permitem identificar com clareza a situação atual de cada um no que se refere ao desenvolvimento sustentável. A Figura 6 permite identificar quais os indicadores que impulsionam o desenvolvimento sustentável nos PA estudados e aqueles que o retardam.

Considerando o exposto, o PA Paraná do nordeste goiano não é sustentável. A falta de integração entre as dimensões da sustentabilidade compromete todas as funções de uso das terras. A sustentabilidade ambiental é a única que atualmente apresenta bom desempenho, mas depende da não alteração do uso do solo, que aumentaria o potencial de perda de solos por erosão. Suas terras têm restrições produtivas extensas, inviabilizando qualquer tipo de exploração econômica tradicional, comprometendo as funções econômicas inerentes à terra. $\bigcirc$ emprego/ocupação e a renda são completamente dependentes de atividades externas e esporádicas que geram insegurança e instabilidade econômica às famílias. A falta de alguns serviços básicos fundamentais e a precariedade de outros geram insatisfação, reduzem a fixação do assentado e aumentam a chance de abandono do lote. Inexiste associativismo e subsequentes ações práticas. 
O PA Boa Esperança foi considerado moderadamente sustentável. Alguns indicadores mostram problemas. Contudo, podem ser revertidos, principalmente por meio da organização produtiva, da adoção de práticas coletivas, da redução da dependência exclusiva do leite, da adequação do uso à capacidade de uso e aproveitando mais o potencial produtivo de suas terras. $\bigcirc$ acesso a serviços básicos existe, supre as necessidades básicas, porém necessita ser melhorado. $\bigcirc$ associativismo tem adesão fraca a moderada e precisa ser aperfeiçoado a fim de ter mais impacto.

\section{Figura 5 - PA Paraná e PA Boa Esperança: comparativo entre a}

\section{sustentabilidade}

LEGENDA
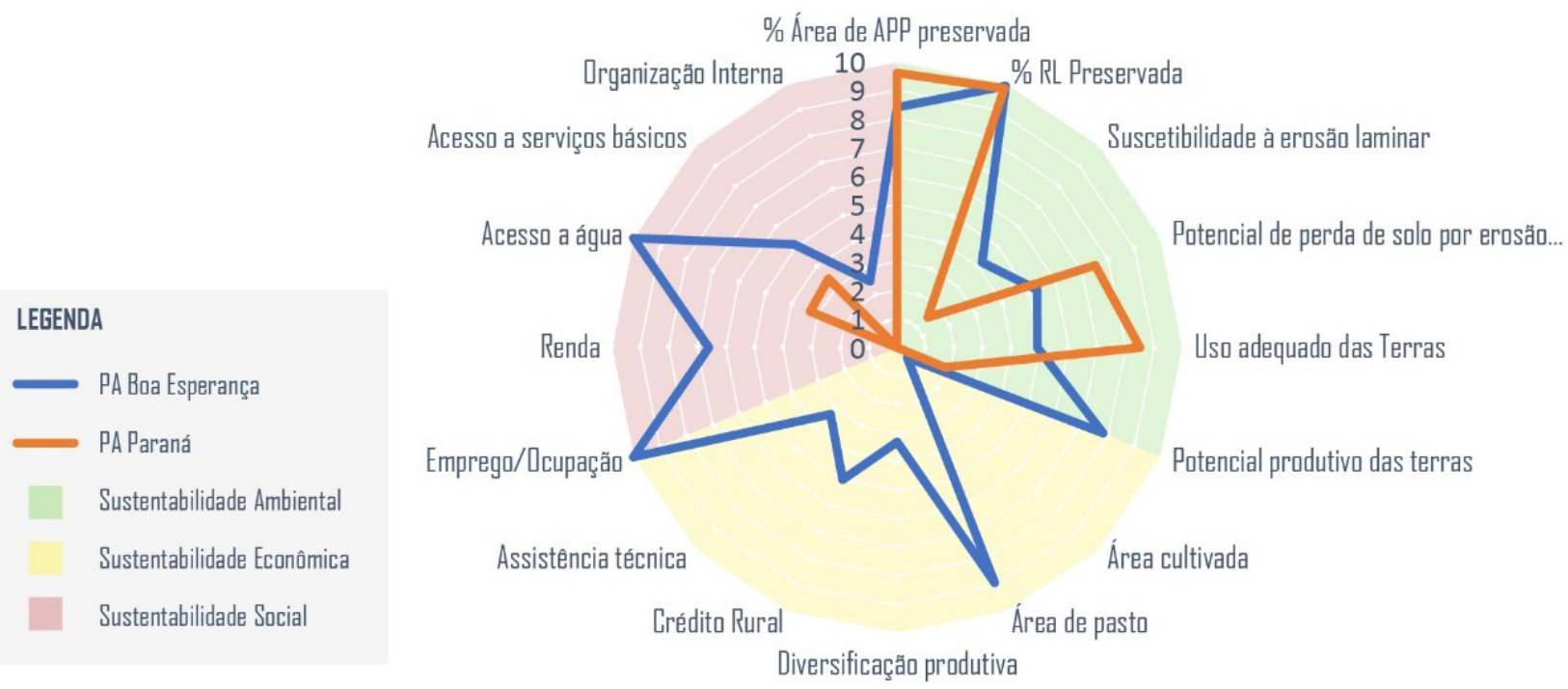

elaboração: Os autores, 2019.

Figura 6 - PA Boa Esperança e PA Paraná: fatores que impulsionam e retardam o desenvolvimento sustentável

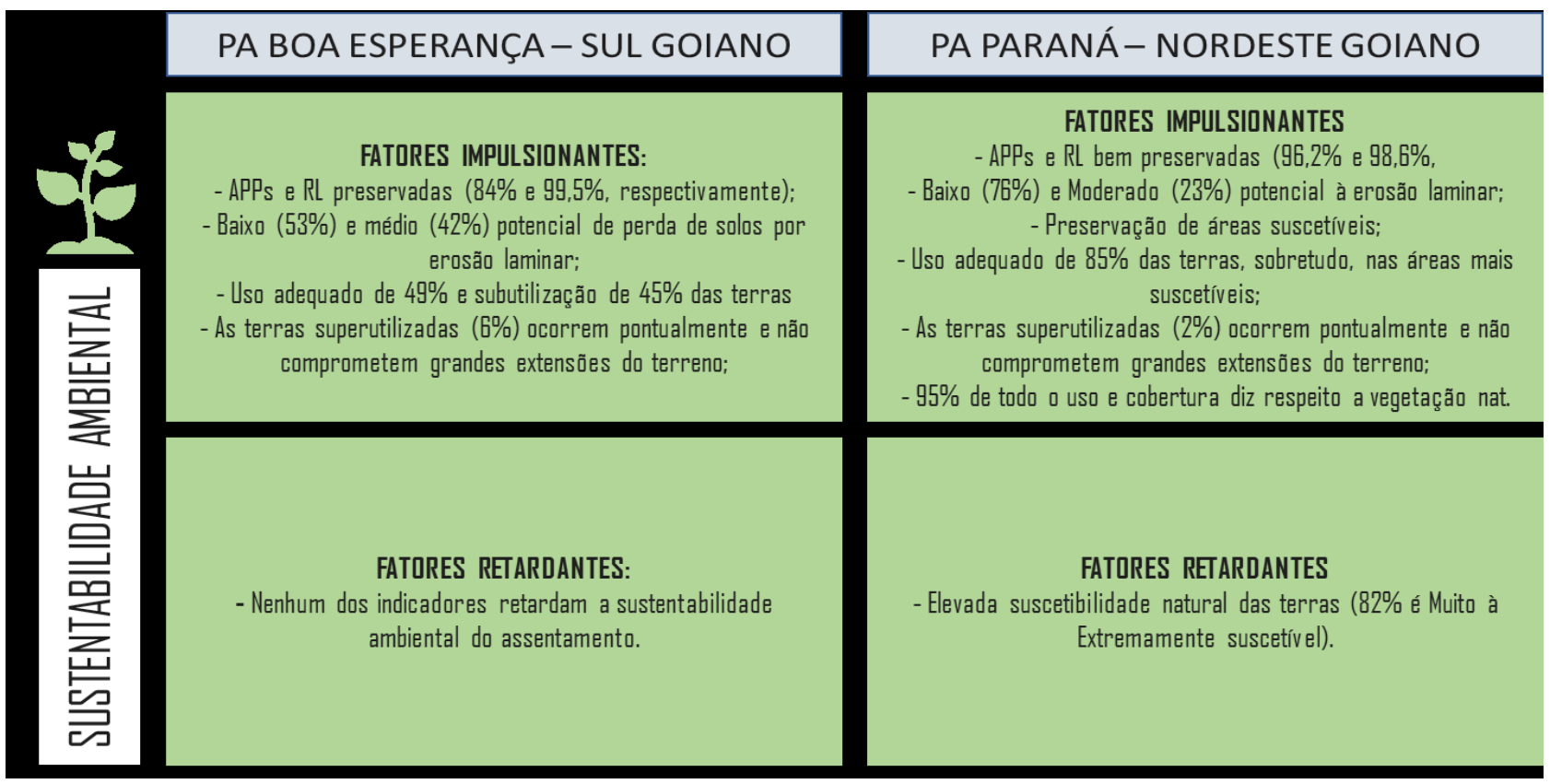




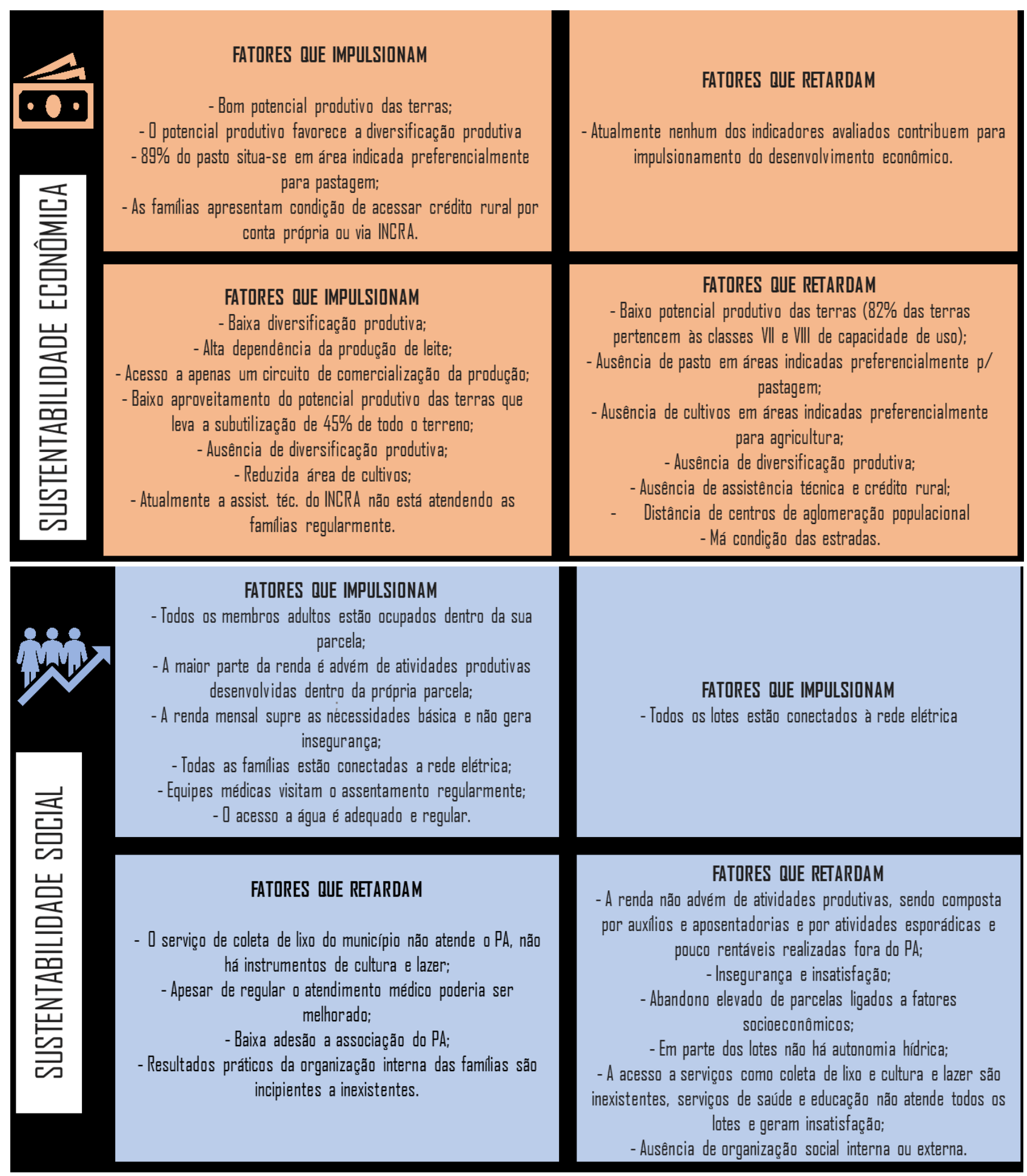

elaboração: Os autores, 2019.

\section{Conclusões}

Os resultados permitem considerar que o componente regional tem forte influência sobre o desenvolvimento sustentável dos assentamentos goianos, sobretudo as diferenças ligadas à oferta de serviços, disponibilidade, proximidade e integração com circuitos de comercialização da produção e às características morfopedológicas das terras, ou seja, de relevo e solo. 
No sul goiano, a combinação entre boas condições produtivas das terras e integração econômica ao contexto local mostra um sistema produtivo que se consolidou favorecendo renda e emprego. $\bigcirc$ melhor desempenho dos indicadores indica condições de sustentabilidade.

No nordeste goiano, a falta dessa combinação e de um planejamento do uso considerando as potencialidades ambientais da área, por exemplo, para fins turísticos, inviabilizou o assentamento em termos econômicos, afetando negativamente o emprego e a renda das famílias. $\bigcirc$ quadro geral instaurado reduz as chances de sustentabilidade na região.

\section{Referências}

ANJOS, F. S. Pluriatividade e desenvolvimento rural no sul do Brasil. Caderno Ciência E Tecnologia, Brasília, v. 20, n 1, p. 11-44, jan./abr. 2003.

ARRAIS, T. P. A. Goiás: novas regiões ou novas formas de olhar velhas regiões. In: ALMEIDA, M. G. (Org.). Abordagens geográficas de Goiás: o natural e o social na contemporaneidade. Goiânia: UFG, 2002. v. 1. p. 147-175.

ARRAIS, T. A.; SALGADO, T. R.; LIMA, L. O.; PINTO, J. V. C. Impactos territoriais dos programas estaduais de intervenção regional no Centro-Oeste: NE e N goiano e entorno do Distrito Federal (1998-2006). Mercator, v. 9, n. 18, p. 39-52, jan./abr. 2010.

BITTENCOURT, G. A.; CASTILHOS, D. S. B.; BIANCHINI, V.; SILVA, H. B. C. Principais fatores que afetam o desenvolvimento dos assentamentos de reforma agrária no Brasil. Projeto de cooperação técnica Incra/FAO. Brasilia, 1999.

BRASIL. MINISTÉRIO DO MEIO AMBIENTE. Mapeamento do uso e cobertura do Cerrado: projeto TerraClass Cerrado 2013. Brasilia: MMA, 2015.

CALAÇA, M.; DIAS, W. A. A modernização do campo no cerrado e as transformações socioespaciais em Goiás. Campo-Território, v. 5, n. 10, p. 312-332, 2010.

CARVALHO, G. L. Entre a pobreza econômica e o patrimônio ambiental/cultural: desafios e possibilidades do turismo no nordeste Goiano. In: ENCONTRO NACIONAL DE TURISMO COM BASE LOCAL, 8., 2004, Curitiba. Anais... Curitiba: Unicenp/ UFPR, 2004.

CASTRO, J. D. B.; XAVIER, G. L. Modificações na estrutura produtiva de Goiás e a inserção econômica do nordeste goiano pós década de 1980. Revista de Economia da UEG, Anápolis, v. 2, p. 1-12, 2006.

CHRISTALLER, W. The central places in southern Germany. Englewood Cliffs, NJ: Prentice Hall, 1966.

CORREIA, S. P. S. A construção de Goiás: ensaio de desenvolvimento político e regional. Goiânia: Ed. PUC, 2010. 
ESTEVAM, L. O tempo da transformação. Goiânia: Editora do Autor, 1998.

GRAZIANO DA SILVA, J. O novo mundo rural brasileiro. Campinas, SP: Unicamp, 2000.

GRAZIANO DA SILVA, J. A nova dinâmica da agricultura brasileira. Campinas: Unicamp/Instituto de Economia, 1996.

HOGAN, D. J.; CUNHA, J. M. P.; CARMO, R. L. Uso do solo e mudanças de sua cobertura no Centro-Oeste do Brasil: consequências demográficas, sociais e ambientais. In: $\mathrm{HO}$ GAN, D. J.; CARMO, R. L.; CUNHA, J. M. P.; BAENINGER, R. (Org.). Migração e ambiente no Centro-Oeste. Campinas, SP: Unicamp, 2002. p. 149-174.

IANNI, O. Origens agrárias do Estado brasileiro. São Paulo: Brasiliense, 1984.

IBGE. INSTITUTO BRASILEIRO DE GEOGRAFIA E ESTATÍSTICA. Censo Agropecuário. Rio de Janeiro: IBGE, 2006.

IBGE. INSTITUTO BRASILEIRO DE GEOGRAFIA E ESTATÍSTICA. Bases e referências. Disponível em: https://mapas.ibge.gov.br/bases-e-referenciais/bases-cartograficas/malhas-digitais. Acesso em: 3 ago. 2019.

IMB. INSTITUTO MAURO BORGES DE ESTATÍSTICAS E ESTUDOS SOCIOECONÔMICOS. Disponível em: http://wwwold.imb.go.gov.br/. Acesso em: 8 abr. 2019.

INCRA. INSTITUTO NACIONAL DE COLONIZAÇÃO E REFORMA AGRÁRIA. Informações gerais sobre os assentamentos de Reforma Agrária. Painel dos Assentamentos Rurais. Brasilia: Incra, 2017.Disponível em: http://painel.incra.gov.br/sistemas/index.php. Acesso em: 7 jan. 2019.

INCRA. INSTITUTO NACIONAL DE COLONIZAÇÃO E REFORMA AGRÁRIA. Acervo fundiário. Disponível em: http://acervofundiario.incra.gov.br/acervo/acv.php. Acesso em: 8 abr. 2019.

KAGEYAMA, A. et al. $\bigcirc$ novo padrão agrícola brasileiro: do complexo rural aos complexos agroindustriais. In. DELGADO, G.; GASQUES, J. G.; VILLA VERDE, C. M. Agricultura e políticas públicas. Brasilia: IPEA, 1990. p. 113-223.

MIELITZ NETO, C. G. A.; MELO, L. M.; MAIA, C. M. Políticas públicas e desenvolvimento rural no Brasil. Porto Alegre: Ed. UFRGS, 2010.

MIZIARA, F. Expansão de fronteiras e ocupação do espaço no Cerrado: o caso de Goiás. In: DANIEL, M. A.; DAL'LARA, L.; ANACLETO, T. C. S. (Org.). Natureza viva Cerrado. Goiânia: Ed. UCG, 2006. p. 169-196.

NUNES, F. G. Análise exploratória espacial de indicadores de desenvolvimento socioambiental das regiões de planejamento do norte e nordeste goiano. Ateliê geográfico, v. 7, p. 237-259, 2013. 
PEARSON. K. On lines and planes of closest fit to systems of points in space. Philosophical Magazine, v. 2, n. 11, p. 559-572, 1901. Disponível em: http://www.stats.org.uk/pca/ Pearson1901.pdf. Acesso em: 23 ago. 2018.

PÉREZ-SOBA, M.; PETIT, S.; JONES, L.; BERTRAND, N.; BRIQUEL, V.; OMODEI-ZORINI, L.; CONTINI, C.; HELMING, K.; FARRINGTON, J. H.; MOSSELLO, M. T.; WASCHER, D.; KIENAST, F; GROOT, R. Land use functions: a multifunctionality approach to assess the impact of land use changes on land use sustainability. In: HELMING, K.; PÉREZ-SOBA, M.; TABBUSH, P. (Ed.). Sustainability impact assessment of land use changes. Berlin; New York: Springer, 2008. cap. 19. p. 375404.

PESSOA, J. M. A revanche camponesa: cotidiano e história em assentamentos de Goiás. Tese (Doutorado em Ciências Sociais) - Instituto de Filosofia e Ciências Humanas, Universidade Estadual de Campinas, Campinas. 1997.

PESSÔA, V. L. S.; INOCÊNCIO, M. E. O prodecer (re)visitado: as engrenagens da territorialização do capital no Cerrado. Campo - Território, v. 9, n. 18, p. 1-22, 2014.

PRADO, L. A.; MIZIARA, F.; FERREIRA, M. E. Expansão da fronteira agrícola e mudanças no uso do solo na região sul de Goiás: ação antrópica e características naturais do espaço. Boletim Goiano de Geografia, v. 32, p. 151-165, 2012.

SANTOS, J. G. R. Sustentabilidade de assentamentos rurais no estado de Goiás: avaliação comparada entre assentamentos do nordeste e do sul goiano. Dissertação (Mestrado em Análise Ambiental e Tratamento da Informação Geográfica) - Instituto de Estudos Socioambientais, Universidade Federal de Goiás, Goiânia, 2018.

SANTOS, J. G. R.; CASTRO, S. S. Influência do meio físico na produção dos assentamentos rurais das regiões do sul e do nordeste goiano. Sociedade $\mathcal{E}$ Natureza, Uberlândia, v. 28, n. 1, p. 95-115, abr. 2016. Disponível em: http://www.scielo.br/scielo. php?script=sci_arttextEpid=S198245132016000100095Elng=enE $\mathrm{nrm}=$ iso. Acesso em: 27 set. 2016.

SILVA, V. M. História agrária em Goiás. Goiânia: Alternativa, 2003.

SMITH, L. A tutorial on Principle Components Analysis. 2002. Disponível em: http:// www.iro.umontreal.ca/ pift6080/H09/documents/papers/pca_tutorial.pdf. Acesso em: 12 dez. 2016.

SPAROVEK, G. Análise territorial da produção nos assentamentos. Brasília: Ministério do Desenvolvimento Agrário: Nead, 2005.

SPAROVEK, G. A qualidade dos assentamentos de reforma agrária brasi-

leira. São Paulo: Páginas E Letras, 2003. 